\title{
Mitigating and adapting to climate change: a call to public health professionals
}

\author{
Mirko S. Winkler • Martin Röösli • Martina S. Ragettli • Guéladio Cissé • \\ Pie Müller · Jürg Utzinger $\cdot$ Laura Perez
}

Published online: 31 July 2015

(C) Swiss School of Public Health 2015

In December 2015, representatives of 196 countries will meet in Paris for the United Nation Framework Convention on Climate Change's Conference (UNFCC) to sign a new climate change treaty that will come into force in 2020. It perhaps represents the last opportunity to shape the zerocarbon society by 2050 that might limit global warming to below $2{ }^{\circ} \mathrm{C}$, which is considered the tipping point for irreversible changes (http://earthstatement.org).

Experts in the public, international and global health arena have been instrumental in changing the paradigm on the impacts of climate change. From an initial threat that focussed exclusively on the environment, climate change is now understood to also have diverse and interconnected consequences for health (McMichael 2013). As epidemiologists and public health professionals, can we stop here? Can we pass to other pressing issues and let others decide on the course of actions? Public health professionals can and must continue to play a crucial role in the climate change debates. Here is why.

Climate change is real (Gleick et al. 2010). Although direct health impacts of climate change are, on average, expected to be only modest in countries of the Northern hemisphere, specific population groups might be affected disproportionally (OcCC/ProClim 2007). We know that people with pre-existing disease and the elderly are

M. S. Winkler · M. Röösli · M. S. Ragettli · G. Cissé ·

P. Müller · J. Utzinger · L. Perez $(\bowtie)$

Swiss Tropical and Public Health Institute,

Socinstrasse 57, P.O. Box, CH-4002 Basel, Switzerland

e-mail: 1.perez@unibas.ch

URL: http://www.swisstph.ch

M. S. Winkler · M. Röösli · M. S. Ragettli · G. Cissé ·

P. Müller · J. Utzinger · L. Perez

University of Basel, Basel, Switzerland particularly vulnerable to extreme heat waves, which will occur more often in the future (Grize et al. 2005; Pascal et al. 2012). People who suffer from allergies are at elevated risks with prolonged pollen seasons. The invasion and reproduction of the Asian tiger mosquitos (Aedes albopictus) across Europe that carry dengue and chikungunya represents a new risk for disease outbreaks, likely to have more serious consequences for those with poorest health and access to care. Hence, mapping and prediction of health vulnerabilities is urgently needed to design adaptation strategies for the foreseeable future. The strategies adopted after the 2003 heat wave that hit parts of Europe have been remarkable in preventing subsequent health impacts, and thus demonstrate the resilience of developed countries on that matter (Fouillet et al. 2008). Nonetheless, new research is needed to ensure that adaptation strategies do not counteract with long-term mitigation actions. For example, reliance in air conditioning - as some governments have proposed-to avoid public health impacts during heat waves could increase energy demand and potential toxic emissions with consequences for health and also for the climate in the long run.

Public health considerations should be part of all climate change strategies because there is a large synergy between those and health promotion. In fact, most of the mitigation measures are beneficial for both climate and human health (Cheng and Berry 2013; Yip et al. 2013). For instance, changes in the transport infrastructure aimed at reducing $\mathrm{CO}_{2}$ emissions result in a reduction of short-lived pollutants such as black carbon (soot) or increased physical activity eventually beneficial for health. To date, these synergies are still largely unknown, even among health professionals. We applaud the initiative of the Swiss Public Health Conference for selecting climate change and health the main theme for this year's annual conference, to take 
place in Geneva on September 17-18, 2015. We look forward to the scientific debates and policy dialogues.

Mitigating the consequences of climate change in the future will largely depend on the capacity and will of key emitters in reducing their greenhouse gas (GHG) emissions. Hence, Switzerland and other high-income countries must drive innovations to reduce GHG emissions and thus minimize their global footprint. They have an important share in the consequences of global warming that have and will primarily materialise in low- and middle-income countries. Indeed, the most recent Intergovernmental Panel on Climate Change (IPCC) report shows-once againthat poorest people will be hit the hardest by the impact of climate change due to their high dependence on ecosystem goods (e.g. food and clean air) and the services they provide (e.g. freshwater purification, protection from natural hazards, climate regulation and sequestration of pollutants) (IPCC 2014; Jackson et al. 2013; Patz et al. 2007). To respond to an increase in illnesses related to more frequent extreme weather events, water pollution, emergence and re-emergence of infectious diseases, food shortage and population migration - to name a few of human-induced climate changes over the next decades-it is crucial that public health experts participate actively and in a timely manner.

Public health professionals need and have the responsibility to be at the forefront in shaping strategies tailored to specific social-ecological settings to reduce impact and vulnerability of climate change and increase resilience. Here, we call for a strong representation and leadership of public health professionals to the coming UNFCC in Paris to ensure the message gets reinforced: health matters are at stake.

\section{References}

Cheng JJ, Berry P (2013) Health co-benefits and risks of public health adaptation strategies to climate change: a review of current literature. Int J Public Health 58:305-311

Fouillet A, Rey G, Wagner V, Laaidi K, Empereur-Bissonnet P, Le Tertre A et al (2008) Has the impact of heat waves on mortality changed in France since the European heat wave of summer 2003? A study of the 2006 heat wave. Int J Epidemiol 37:309-317

Gleick PH, Adams RM, Amasino RM, Anders E, Anderson DJ, Anderson WW et al (2010) Climate change and the integrity of science. Science 328:689-690

Grize L, Huss A, Thommen O, Schindler C, Braun-Fahrländer C (2005) Heat wave 2003 and mortality in Switzerland. Swiss Med Wkly 135:200-205 (2005/13/smw-11009)

IPCC (2014) Climate change 2014: impacts, adaptation, and vulnerability. Part A: global and sectoral aspects. In: Field CB, Barros VR, Dokken DJ, Mach KJ, Mastrandrea MD, Bilir TE et al (eds) Contribution of Working Group II to the Fifth Assessment Report of the Intergovernmental Panel on Climate Change. Cambridge University Press, Cambridge, UK and New York, NY, USA

Jackson LE, Daniel J, McCorkle B, Sears A, Bush KF (2013) Linking ecosystem services and human health: the Eco-Health Relationship Browser. Int J Public Health 58:747-755

McMichael AJ (2013) Globalization, climate change, and human health. N Engl J Med 368:1335-1343

Pascal M, Le Tertre A, Saoudi A (2012) Quantification of the heat wave effect on mortality in nine French cities during summer 2006. PLoS Curr 4:RRN1307

Patz J, Gibbs H, Foley J, Rogers J, Smith K (2007) Climate change and global health: quantifying a growing ethical crisis. EcoHealth 4:397-405

OcCC/ProClim (2007) Klimaänderung und die Schweiz 2050. Erwartete Auswirkungen auf Umwelt, Gesellschaft und Wirtschaft. Bern

Yip CS, Crane G, Karnon J (2013) Systematic review of reducing population meat consumption to reduce greenhouse gas emissions and obtain health benefits: effectiveness and models assessments. Int J Public Health 58:683-693 